\title{
The Influence of Linguistic Landscape on the Image of Shenzhen
}

\author{
Wenxia Zeng, Jing Luo* \\ English Department, Shenzhen Tourism College, Jinan University, Shenzhen, China \\ Email: *ivyluojing@163.com
}

How to cite this paper: Zeng, W.X. and Luo, J. (2019) The Influence of Linguistic Landscape on the Image of Shenzhen. Open Journal of Social Sciences, 7, 112-125. https://doi.org/10.4236/jss.2019.73008

Received: December 24, 2018

Accepted: March 5, 2019

Published: March 8, 2019

Copyright $\odot 2019$ by author(s) and Scientific Research Publishing Inc. This work is licensed under the Creative Commons Attribution International License (CC BY 4.0).

http://creativecommons.org/licenses/by/4.0/

\begin{abstract}
With the development of globalization, linguistic landscape is becoming a popular linguistic phenomenon. In the meantime, Chinese scholars' research on linguistic landscape is also developing. As a coastal city of China and the important port for the opening up policy, Shenzhen shows its advancement in technology and economy. Public signs as a kind of linguistic landscape become a common site to build Shenzhen's image as a metropolitan. This thesis mainly focuses on public signs' functions as linguistic landscape and Shenzhen's image. The data will be collected from different scenic spots and public places of Shenzhen, such as Happy Valley, the Splendid China and the Airport, etc. By case analysis, this thesis will find out the positive and negative examples of Shenzhen's public signs' translation and analyze their impacts on Shenzhen's image. Finally, this thesis will give some suggestions for improvement of city image.
\end{abstract}

\section{Keywords}

Linguistic Landscape, Skopos Theory, City Image

\section{Introduction}

\subsection{Research Background}

The study of linguistic landscape started in 1997 by Landry and Bourhis [1]. With the development of linguistic and globalization these years, the study of linguistic landscape began to concern about the bilingual and multilingual environment of the linguistic landscape to analyze how the languages on the linguistic landscape reflect the social linguistic in a certain region. Or it is to find out how the linguistic landscape reflects the culture features in a certain region. Chinese scholars started to study linguistic landscape in the 21 st century and mainly fo${ }^{*}$ Corresponding author. 
cused on geographical linguistics, social linguistics and the translation of the linguistic landscape. However, we still lack of theoretical support and there are few studies that mainly work on the linguistic landscape in a specific place, let alone analyzing the linguistic landscape and relating it to the image of a city.

As for the public signs, a part of linguistic landscape, most of the studies are analyzing its translation with different theories, trying to figure out the mistakes and the reasons that cause those mistakes and giving suggestions for correcting the mistakes. Although some studies use Skopos Theory to analyze the functions of the public signs and the image of a city, few studies connect linguistic landscape's functions to the public signs.

Shenzhen is a metropolitan of China. With the development of world economy and globalization, Shenzhen is developing into an international city. Public signs as linguistic landscape are an important part of Shenzhen's tourist attractions. Therefore, the translation of public signs has great impact on Shenzhen's city image construction. Former studies on Shenzhen's public signs' translations have no relations with public signs' function as linguistic landscape and Shenzhen's city image.

\subsection{Focus and Significance}

Since previous studies on linguistic landscape barely focus on the relation between translations and the functions, those studies on the functions of public signs and the image of city neglect public signs' functions as linguistic landscape. So this thesis will study public signs' functions as linguistic landscape. They are informational function and symbolic function.

Previous studies on translations mainly work on the mistakes and reasons for mistakes as well as corrections for mistakes of public signs' translation. However, this thesis will focus on how public signs' translations affect public signs' functions and how these effects influence the image of Shenzhen. With the development of globalization, Shenzhen is becoming an international tourism city. Therefore, this thesis will mainly focus on Shenzhen's virtual image as an international tourism city.

According to the analysis, some translations of Shenzhen's public signs are far away from specific and standard. This thesis will figure out those inappropriate translations and give suggestions for improvement, which is helpful for Shenzhen to maintain and improve its image as an international city. It is also important for Shenzhen's social, cultural and economic development. Thus, this thesis will be significant for Chinese academic development and the development of Shenzhen city.

\section{Literature Review}

\subsection{Definition of Linguistic Landscape}

Linguistic landscape plays an important role in the urban landscape and it has great impacts on the image of a city. With the development of economic globa- 
lization and urban internationalization, linguistic landscape has been paid more and more attention recently.

The term linguistic landscape was first used by Landry and Bourhis (1997) as: The language of public road signs, advertising billboards, street names, place names, commercial shop signs, and public signs on government buildings combines to form the linguistic landscape of a given territory, region, or urban agglomeration [1]. Xia $\mathrm{Na}$ (2014) mentions four definitions in her paper [2]. The first one is the definition by Landry and Bourhis. The second one is provided by Itagi and Singh. They consider linguistic landscape as "language use in its written form (visible language) in the public sphere". It can be therefore concluded that all written forms inside a certain area would be study objects of the research of linguistic landscape. The third is from Gorter, who points out: according to the dictionary, landscape as a noun has two meanings: in the more literal meaning of the piece or expanse of scenery that can be seen at one time from one place, and a picture representing such a view of natural inland scenery. He further analyzes that in the studies of the linguistic landscape, both of the meanings were employed [3]. Gorter also mentions that Linguistic landscape is, "the literal study of the language as they are used in the signs the representation of the languages, which was of particular importance because it relates to identity and cultural globalization, to the growing presence of English and to revitalization of minority languages" [4]. The fourth one is explained by Ben-Rafael that "linguistic landscape refers to linguistic objects that mark the public space" [5]. To better define this term, they state that linguistic landscape as any sign or announcement located outside or inside a public institution or a private business in a given geographical location. In their perspective, the definition of linguistic landscape seems to be broader, which means that they not only focus on signs inside a public institution or a private business, but also signs outside these places or buildings.

Wan Yongkun and Yuan Yichuan (2016) conclude that what Sun Li (2009) mentions about linguistic landscape means the written language of signs in public places and the researches on linguistic landscape is to do researches on written language of public signs [6] [7]. Li Lisheng (2015) regards linguistic landscape as a branch of applied linguistic and social linguistic. She divides language landscape into two major categories, one is top-down category, i.e. official and public linguistic landscape, including name of governmental institutions, official announcement, name of the streets and the public service advertising; another is bottom-up category, i.e. private and commercial linguistic landscape, including private shops, hotels, jewelry stores and advertising [8]. Liang Linxin (2013) lists the definition of public signs from Longman Dictionary of Contemporary English: a piece of paper, metal etc. in a public place, with words or drawing on it that give people information, warn them not to do something etc. [9]. The definition of public signs in her paper is a special applied literature form that is used to transmit information or express specific purpose for people in public places, usually showed as written words or icons. 
According to all the definitions mentioned above, this paper will base on this definition: linguistic landscape is the written words and icons of public road signs, advertising billboards, street names, place names, road directions, commercial shop signs, and public signs on government buildings combines to form the linguistic landscape of a given territory, region, or urban agglomeration. Since public signs is a typical kind of linguistic landscape common in our daily life, this thesis's analysis of linguistic landscape will base on the analysis of public signs.

\subsection{Functions of Linguistic Landscape}

Landry and Bourhis (1997) proposed that the linguistic landscape has two basic functions. One is informational function and the other is symbolic function. These two functions of linguistic landscape are the basis of the research of linguistic landscape [1].

Informational function means the written words or icons of the linguistic landscape can transmit the relevant information to the public, i.e. to communicate with them, to inform, direct, guide, or warn them. It is the direct function of linguistic landscape. Most scholars think the informational function of linguistic landscape for the basic function that make the linguistic landscape exists.

Since the linguistic landscape (including marks, signs, guideboard, name of institutions and announcements, etc.) is always bilingual or multilingual, the absence or existence of a language on linguistic landscape can represent the importance or social status of the language in a certain region. It can also have great impact on those who speak the language because it can also reflect the social status, cultural status and social power of those who speak the language. This is called the symbolic function.

According to some research, the immigrants or foreign tourists can feel great respects from the written words of their language on the linguistic landscape. Therefore, the development of Chinese economy and tourism require people to think highly of the symbolic function of linguistic landscape.

\subsection{City Image}

The concepts of city image and its theory were first mentioned in China in the 1990s by Professor Luo Zhiying in Lanzhou University. With these years' development, the definition of city image varies and more and more Chinese scholars start to focus on the development of city with its city image.

Chinese Scholars' definition of city image can be divided into three major groups. One is the impressionism, which believes city image is the overall impression and assessments of the public on this city. Secondly it is the imagism, which defines city image as the features of city's landscape and the manifestation of the city's properties, structure and functions. Thirdly it is from those who regard city image as the cultural spirit of the city and the important intangible asset of the city. Though the definition on city image varies, most of the scholars 
reach the agreement that city image is the external manifestation of the city's culture, spirit and landscape. It's also people's overall impression and assessments of the city and the city's significant intangible asset.

City image is actually a big system with several subsystems, which can be influenced by historical factors, political factors, economic factors and cultural factors, etc. It's people's impression of the city's comprehensive strengths.

\subsection{Research on City Image}

The concept of city image was first mentioned by Kevin Lynch, an American scholar in 1960. There are many researches on city image in China now. According to the researches on city image collected from CNKI, it can be divided into three major groups. The first is the researches on the molding of the city image (Zhang Yunbin and Wu Wei (2010) [10] etc. The second is the researches on the dissemination of the city image (Chen Liuqin (2011) [11]. The third, there are some researches mainly focus on the theories and methodologies of the research on city image. They talk about the management system of city image. They also point out that Chinese scholars have make researches on the connotation structure of the city image, the necessity of molding the city image, the orientation of city image, the design of city image, the upgrading of city image, the dissemination and marketing of city image and the assessment of city image, which helps to form a complete management system of city image.

According to the analysis of these researches, there have been lots of researches on city image and how to improve the image of a certain city. But, because linguistic landscape is a relatively new concept for Chinese scholars, research on the combination of linguistic landscape and the image of a city is few. As city image is important for the economic and cultural development of a city, it's significant to know the relations between linguistic landscape and the image of a city. With the development of reform and opening up policy, Shenzhen is developing into an international tourism city, the research of this thesis is full of importance for the further development of Shenzhen.

\subsection{Skopos Theory}

The Skopos Theory was established by two German linguists, Hans J. Vermeer and Katherina Reiss in 1970s. It is a theory for translation studies that emphasize bringing the target text into focus and it has three core principles. They are skopos principle, coherence principle and loyalty principle. Skopos principle requires translators and interpreters to pay more attention to the aim and purpose of the target text when doing translation and interpretation. Coherence principle means the translated text should make sense and be appropriate in certain communicative situation. It requires translators and interpreters to make their translated text understandable. Loyalty principle is also called function plus loyalty principle. It was founded by another German scholar named Christiane Nord. It requires the translated text to be coherent with the source text. Not only 
should the functional purpose be realized, but the translated text should also be coherent with the communicative situation and the style should be as the same as the literature style of the source text.

Since public signs are mainly set in certain place to inform, direct, guide, warn and restrict people, the translation of public signs should take the Skopos principle as the most important principle to obey. This thesis mainly uses Skopos Theory to analyze the translation of Shenzhen's public signs.

According to the analysis of previous studies on Skopos Theory and the studies on translation of public signs, it is found no study using Skopos Theory to analyze the translation of public signs and further try to figure out the relation between public signs' translation and its function, as well as the image of a city. This is also the significance and innovation of this thesis.

\section{Methodology}

\subsection{Data Collection}

The data of this thesis is collected from some public places, such as the airport and subway station and some places of interests of Shenzhen, such as Happy Valley and the Splendid China, etc. The reasons are as follows. First, public signs at these places are more likely to be bilingual with representing the actual linguistic environment of Shenzhen. Besides, the translations of public signs at these places have great influence on Shenzhen's image as an international tourism city. Therefore, the analysis of public signs' translation at these places is typical.

As the data was collected from different places, digital camera and cell phone were used to collect the works. The quantity of all the photos is 346 and the basic information of the data can be shown as Table 1.

\subsection{Procedures of the Research}

This thesis will start at dividing the photos into different categories. Firstly it is to figure out the translations with negative and positive impact on Shenzhen's city image. Secondly, authors will study these translations into different groups. The translation that has negative impact is the mistakes of translation. These translations can be divided into three groups as spelling mistakes, grammatical mistakes and the mistakes caused by cultural difference. Moreover, the translations that have positive impact can be divided into three major groups. They are brief in form, fit cultural differences and accurate in meaning. Thirdly, the paper will analyze what function of public signs as linguistic landscape. Fourthly, as this paper is to figure out the relation between public signs' translation and the image of Shenzhen, the relations between the effects on functions and the image of Shenzhen as an international tourism city will also be explained. Finally, the findings will be concluded, suggestions for improvement will be provided and there will be a discussion on the findings and further research. 
Table 1. Basic information of the data.

\begin{tabular}{ccc}
\hline Place & Quantity & Proportion \\
\hline OCT & 41 & $11.85 \%$ \\
Happy Valley & 44 & $12.72 \%$ \\
Splendid China & 216 & $62.43 \%$ \\
Subway Station & 17 & $4.91 \%$ \\
Shenzhen Airport & 28 & $8.09 \%$ \\
Total & 346 & $100 \%$ \\
\hline
\end{tabular}

\section{Case Analysis of Shenzhen's Public Signs}

This part will present three kinds of public signs' translations that have negative impact on Shenzhen's image. That is the mistakes of translations. Moreover, three kinds of translations that have positive impact on Shenzhen's image will also be introduced. In addition, it will also analyze the impact as well as the image of Shenzhen as an international tourism city. Finally, a conclusion will be made and suggestions for the improvement of public signs' translation and the image of Shenzhen will be offered.

\subsection{Mistakes of Public Signs' Translations}

According to the analysis of data that collected from Shenzhen Airport, OCT, the OCT subway station, Happy Valley and Splendid China, many mistakes of public signs' translation in these places were found. The mistakes can be divided into three major kinds as Table 2 while the details of the analysis will also be provided.

\subsubsection{Spelling Mistakes}

The spelling mistakes are very apparent on public signs. Spelling mistakes can have negative influence on public's understanding of the public signs. As some mistakes are stupid, it will have very bad influence on the image of a city.

According to the analysis of the data collected, both of the two spelling mistakes are found from the data of Splendid China. One is the translation of “请勿 翻越”. It is translated as “No Grossing”, which should be “No Crossing” actually. The other is the translation of “请保持观赏距离, 注意小孩的安全”. The translation is "please keep zhe viewing distance, pay attention to the safety of chidren". There are two spelling mistakes of this translation, "zhe" should be "the" and "chidren" should be "children".

\subsubsection{Grammatical Mistakes}

Grammatical mistakes are also found in the data collected from OCT, Happy Valley and the Splendid China. The basic information of the grammatical mistakes can be shown as Chart 1 . 


\section{Grammatical Mistakes}

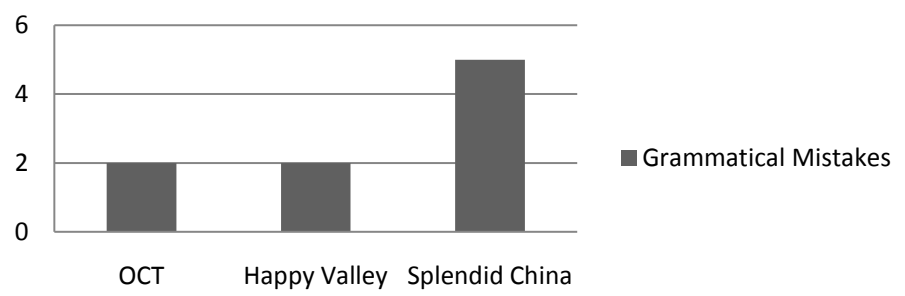

Chart 1. Basic INFORMATION of the grammatical mistakes.

Table 2. Basic information of the types of the mistakes.

\begin{tabular}{ccc}
\hline Types & Quantity & Proportion \\
\hline Spelling Mistakes & 2 & $0.58 \%$ \\
Grammatical Mistakes & 9 & $2.60 \%$ \\
Cultural Mistakes & 5 & $1.45 \%$ \\
\hline
\end{tabular}

According to the analysis of the grammatical mistakes, it is found that some of these mistakes are caused by choosing the inappropriate words while others are caused by literal translation of Chinese. No matter what are the reasons for these mistakes, the grammatical mistakes may mislead people and the wrong translation may influence the informational function of public signs and therefore influence the image of Shenzhen city. The cases analysis can be listed as follows.

Two grammatical mistakes are found from the data of OCT. First is the translation of “小心夹伤” as “Carefully clamp injury”, which makes no sense in English. It is the translation from Chinese word by word but ignores the meaning of the source text and the target text. It's better to be translated as "Caution, clamped”. Next is the translation of “防火卷帘下严禁堆放物品” as “Fire shutter down keep clear". In this sentence, “下” means "under the fire shutter", so it should not be translated into "down". It's a grammatical mistake. A better version of this sentence's translation can be "Fire shutter, please keep clear". There is a grammatical mistake found from the data of Happy Valley, too. It is the translation of “入口" as "Way in". But it would better to translate it as "Entrance".

In the most popular theme park, the Splendid China, five grammatical mistakes are found. First is the translation of “围观游客请勿靠近” as “Other tourists around, Please keep off”. It can be translated as “Tourists please keep off". The second one is the translation of “此处水深, 请勿跨越” as “BE CAUTION, NO CLIMBING". In this translation, "caution" should be "cautious". The third one is the translation of a kind of animal. The translation of “山羊” is written as "blue sheep" while there is a word for “山羊” in English. It is "goat". The next one is the translation for “抱” as "carry in the arms". But the word "hug” in English means “抱” in Chinese. The final is the translation of “危险请勿靠近” as "Danger do not close to". This translation is hard to understand for English-speaker. It's better to be translated as "Dangerous, do not approach". 


\subsubsection{Mistakes Caused by Cultural Difference}

Mistakes caused by cultural difference also exists in public signs translations. Since the translation is to help the target receiver know the exact meaning of the original text, cultural difference should be taken into consideration when doing the translation. However, translators may forget to think about cultural difference sometimes and that may cause mistakes of translation.

According to the data collected from Happy Valley, mistake caused by cultural difference are found. The translation of “黄金周除外” in Happy Valley may make people misunderstand the actual meaning of the public signs. It is translated as “Excluding holidays". However, “黄金周” in Chinese means golden week, which is not the same as holidays. The golden week in China is the National Holiday. Therefore, the accurate translation should be "Excluding National Holiday".

\subsection{Negative Impact on Shenzhen's Image}

According to the analysis of the data collected from the public places of Shenzhen, some mistakes are found and there is no doubt that these mistakes will absolutely play negative impact on the image of Shenzhen.

The spelling mistake is apparent and some of them may have no influence of people's understanding of the public signs, however, this kind of mistake disobeys the three principles of Skopos Theory. It can hardly meet the requirements of Skopos principle, coherence principle and loyalty principle. Moreover, since it can be avoided by double check and careful work, it is kind of the stupid mistake and has very bad influence on the image of the city image.

The grammatical mistake disobeys two of the three principles of the Skopos Theory. They are Skopos principle and the coherence principle. The grammatical mistake disobeys the Skopos principle because it may lead to the misunderstanding of the public signs, which can not realize the purpose of the target text. Moreover, it also disobeys the coherence principle because it is definitely inappropriate in the circumstance and is not understandable sometimes. This kind of mistake may influence the informational function of public signs as linguistic landscape and therefore may influence the cultural image of Shenzhen because it can't express the connotation of Shenzhen and may leave the pubic an impression that Shenzhen lack of talents to do grammatically correct translation of the public signs, which may also influence the development of Shenzhen's economy and its economic image.

The cultural mistake disobeys the coherence principle and the loyalty principle of the Skopos Theory. Thus, cultural mistake makes the translation doesn't fit the communicative situation. Since some cultural mistakes make the translations make no sense actually, those translations with cultural mistakes are not understandable. Therefore, it may influence the informational function of public signs as linguistic landscape. Moreover, it can't make the translations meet the purpose and target. Because cultural mistakes are made by different cultures and their expression of certain meanings, the literature style of the source text and 
target text are different. This kind of mistakes gives the native speakers of the target language an impression of disrespect. Therefore it may also influence the symbolic function of the public signs as linguistic landscape. The cultural image of Shenzhen may be shattered.

\subsection{Translations with Positive Impact}

Although there are quite a few mistakes of Shenzhen's public signs' translation, there are also some translations with positive impact on Shenzhen's city image, too. According to the analysis of data collected from Shenzhen Airport, OCT, OCT subway station, Happy Valley and the Splendid China, some positive translations are found. They can be roughly divided into three major groups: translations that are brief in form, translations that fit the cultural differences and translations that are accurate in meaning. The basic information of these cases can be shown as Chart 2 .

\subsubsection{Being Brief in Form}

Translations that are brief in form are found mainly from the data collected from Shenzhen Airport and the subway station. The basic information can be shown as Chart 3.

The details of the analysis are as follows. “禁止吸烟” in Shenzhen Airport and subway station are translated into "No Smoking". Furthermore, in Shenzhen Airport, “小心热水” is translated into “Caution Boiling Water”, “小心跌滑” is translated into "Caution, Slip”, and the translations of both “请节约用纸” and “请节约用水” as “Use as Necessary” are also the cases of affirmative translations that are brief in form. As for the translation of public signs in subway station, the case that “禁止行乞” is translated into “No Begging”, “请勿携带气球” is translated into “No Balloons”, “禁止饮食” is translated into “No Eating or Drinking”, “禁止携带易燃易爆等危险品进站” is translated into “Dangerous Articles Forbidden”, “请勿扶门” is translated into “Do Not Touch” and the case that “禁止 攀登” is translated into "No Climbing" are all the cases of translations that are brief inform.

\subsubsection{The Awareness of Cultural Differences}

The translations that fit the cultural differences are found from the data in subway station and the Splendid China.

For example, the translation of “爱心座椅” is “Priority Seat” and the translation of “请给有需要人士让座” is “Please Offer Seat to Priorities”. The English translation is not from the direct translation of Chinese words but to express the actual meaning of the origin text and make it to be more close to the expression of foreign culture. As for Chinese culture, we emphasize our morality and emotion more, so Chinese version uses “爱心” to convince passengers. However, as for western culture, they emphasize more on whether it is a right thing or not, so there is "priority" in English version. And there is one specific examples found from the Splendid China. The public sign “特别提醒, 游客出门后请重新购票” 
Translations with Positive Impact

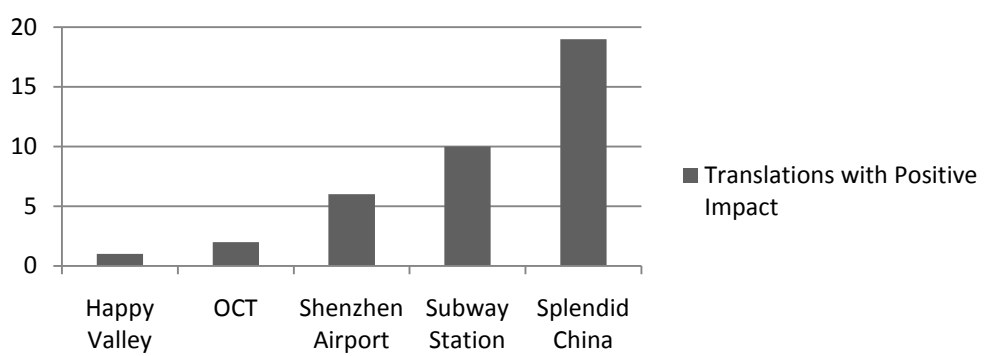

Chart 2. Basic information of translations with positive impact.

\section{Brief in Form Translations}

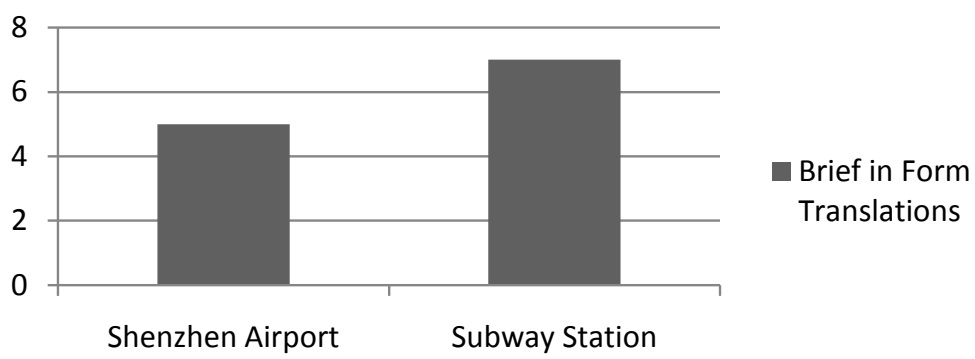

Chart 3. Basic information of brief in form translations.

is translated into "THE ADMISSION TICKET IS VALID FOR ONE ENTRY ONLY”. As for the translation of this public sign, the translation of “特别提醒” is skipped. Because as for Chinese culture, we are relation-oriented, we prefer to be polite by offering information with more words. But actually, in western culture, they are task-oriented, so they love to know the accurate meaning with less word, less time and less room. They prefer to be brief, so the translation is better to skip the translation of “特别提醒” and just offer the emphasized meaning of this sign.

\subsubsection{Being Accurate in Meaning}

As for the translations that are accurate in meaning, quite a few examples are found from Shenzhen Airport, OCT, subway station and the Splendid China. The basic information of these examples can be shown as Chart 4 .

In Shenzhen Airport, there is a translation of “请携带随身物品” as “Keep your belonging in sight". As for the cases of OCT, there are also two cases found. One is the translation of “一品轩”, the name of a bakery, as "bakery coffee life". It is hard and unnecessary to translate “一品轩” literally and "bakery coffee life" can express the functions of this bakery well. It is easier for target receiver to understand and accept the meaning of “一品轩”. The other is the translation of the name of the street “生态广场东街” as “ECOLOGY SQUARE EAST St.”. The translator's choice is to translate the Chinese name of the street without using the pinyin of the street's name as the English translation which makes target receivers easier to understand. There is also one example of OCT subway station 


\section{Being Accurate in Meaning}

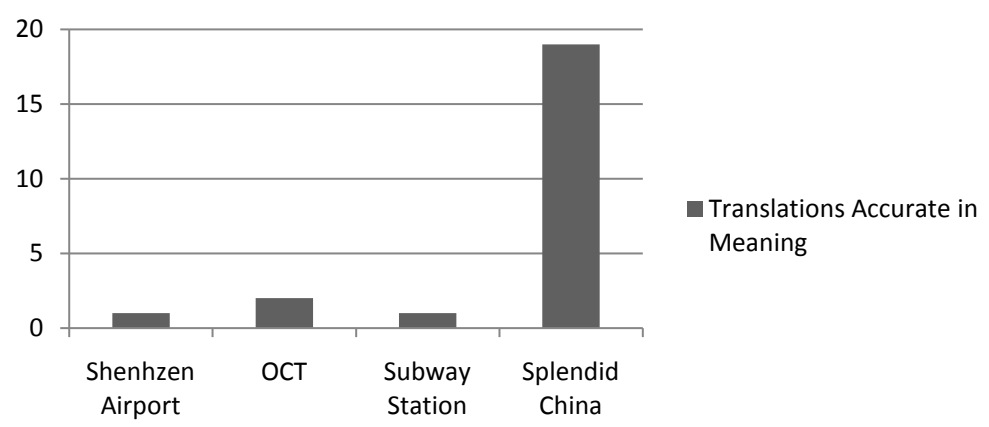

Chart 4. Basic information of translations accurate in meaning.

that belongs to the positive translations. The translation of “请勿冲门” as “Never force your way into the train". In addition, the translations of the names provided in different steles in the Splendid China can also be the cases of affirmative translation. Although the English translation is the pinyin of these names, the translators make further explanations on the meanings of these names in Chinese. For example, “蓬莱阁” is translated as “Penglai Pavilion” and explained as “A Fabled Abode of Immortals”, “万华阵” is translated as “Wan-Hua-Zhen” and explained as “The Maze”, “海晏堂” is translated as “Hai-Yan-Tang Hall” and explained as "Hall of Peace and Prosperity" and “福海” is translated as "Fu-Hai” and explained as "Sea of Fortune", etc. These translations can not only give target receivers the direct pronunciation of the names in Chinese, but also the actual or connotation meanings of these names to achieve better communication.

\subsection{Positive Impact on Shenzhen's Image}

The translations of public signs that have positive impact on Shenzhen's image meet all of the three principles of the Skopos Theory. For the Skopos principle, these translations can make target receivers fully understand the meaning of the source text with the informational function of public signs as linguistic landscape. And as for the coherence principle and loyalty principle, these translations are appropriate to certain communicative situation, and most importantly, they are close to the local expression of the source text. As a result, they are as the same literature style as the source text and can make foreign target receivers understand the meaning perfectly. In addition, because these translations can meet all the requirements of Skopos Theory, it can build up a positive cultural image of Shenzhen and can also represent the development of Shenzhen's culture, education as well as economy, which can help to improve Shenzhen's economic image and comprehensive image as well.

\subsection{Suggestions for Improvement}

According to the mistakes above, there are some suggestions for the improvement of public signs' translation in Shenzhen.

Firstly, doubly checking the words on public signs to avoid spelling mistakes 
and other apparent mistakes is necessary. Secondly, the relevant department should hire professional translators to do the translation of public signs, so that the grammatical mistakes can be avoided. Thirdly, it would be better to learn from the words on public signs that have the same meaning and purpose in English speaking country to make sure that the translation can make sense and won't confuse people. Finally, an investigation among the target receivers of the translation of public signs can make the translations better. Therefore, the mistakes caused by cultural difference can be reduced.

\section{Conclusions}

This thesis aims to analyze public signs' translations in Shenzhen and figure out the relation between public signs' translation and city image. In addition, by analyzing the relation between public signs' translations and its functions, their influence on the image of Shenzhen as an international city is also the main topic for discussion.

The authors figure out the negative and positive examples of public signs' translations by dividing them into several categories. This study has not only analyzed the relation between public signs' translations and its functions, but also discussed the relation between public signs' functions and the image of Shenzhen city. This is significant for the development of Shenzhen city. With Shenzhen's development, more and more immigrants and tourists from countries around the world come to Shenzhen these years. Besides, the bilingual linguistic landscape is also developing in Shenzhen and stands almost everywhere in Shenzhen. Therefore, the bilingual linguistic landscape has great impact on their impression of Shenzhen, which will affect Shenzhen's image.

As this thesis just studies on public signs, one kind of linguistic landscape, these findings are limited. For further research on linguistic landscape and city image, scholars can study on other types of linguistic landscape to broaden its research in this field.

\section{Acknowledgements}

This research is supported by the funding of "the Construction of Qualified University" of Jinan University 2018.

\section{Conflicts of Interest}

The authors declare no conflicts of interest regarding the publication of this paper.

\section{References}

[1] Landry, R. and Bourhis, R.Y. (1997) Linguistic Landscape and Ethnolinguistic Vitality: An Empirical Study. Journal of Language and Social Psychology, 16, 23-49. https://doi.org/10.1177/0261927X970161002

[2] Xia, N. (2014) Linguistic Landscape Studies in Multilingual Region. Yunnan Normal University, Yunnan.

[3] Gorter, D. and Cenoz, J. (2008) Knowledge about Language and Linguistic Land- 
scape. Encyclopedia of Language and Education, 6, 2090-2102.

https://doi.org/10.1007/978-0-387-30424-3_160

[4] Gorter, D. (2006) Introduction: The Study of the Linguistic Landscape as a Newapproach to Multilingualism. International Journal of Multilingualism, 3, 1-6. https://doi.org/10.1080/14790710608668382

[5] Ben-Rafeal, E., Shohamy, E., et al. (2006) Linguistic Landscape as Symbolic Construction of the Public Space: The Case of Israel. International Journal of Multilingualism, 3, 7-30. https://doi.org/10.1080/14790710608668383

[6] Wan, Y.K. and Yuan, Y.C. (2016) The Review of Chinese Studies on Linguistic Landscape. English Square, 5, 17-20.

[7] Sun, L. (2009) Communicative Translation Strategy of Chinese-English Linguistic Landscape Translation. Journal of Jiangxi Normal University, 6, 153-156.

[8] Li, L.S. (2015) Literature Review and Implication of Foreign Linguistic Landscape Studies. The Journal of Beijing International Studies University, 4, 1-7.

[9] Liang, L.Y. (2013) The Classification Studies on Public Sign Translation. Fujian Normal University, Fujian.

[10] Zhang, Y.B. and Wu, W. (2010) The Studies on City Image Construction in the Perspective of City Image System Constructure. Planners, 12, 110-113.

[11] Chen, L.Q. (2011) City Image's Intonation, Position and Effective Publicity. The Journal of Hunan City University, 1, 62-66. 